\title{
Theory of Mind deficits and its impact on language among the Bengali High Functioning Autistic Children
}

\author{
Mir Ushmum Alam \\ Lecturer in English, University of Skill Enrichment and Technology (USET), Dhaka, Bangladesh
}

\begin{abstract}
Theory of Mind (ToM) deficits is one of the major deficits in children with the developmental disorder. In this research, the problems of Theory of Mind in Bengali children with High Functioning Autism (HFA) are tried to be identified. Not only that, the impacts of the deficits of ToM on the language are also analyzed in the research. Data have been collected from 08 High Functioning Autistic children from a reputed autism specialized school. Their chronological age is $\mathbf{1 6 - 2 2}$ and mental age is 8-12. From the findings of the research, the conclusion can be formulated that, ToM deficits hamper their daily lives in many ways and communication. Different types of therapy module can be formulated after considering the result of this paper.
\end{abstract}

Keywords: Theory of mind; High Functioning Autism; Language, Communication.

\section{INTRODUCTION}

$\mathrm{C}$ Oognitive ability is undoubtedly very necessary for the overall growth of an individual. But people with different types of neurodevelopmental deficits have lacked these abilities in many ways. Theory of mind (ToM) is an umbrella term for different types of cognitive ability. It includes mental-physical distinction, understanding the function of the brain, the appearance reality distinction, different people have different thoughts, seeing leads to knowing, recognizing mental state words, using mental state words in spontaneous speech, understanding causes of emotion, spontaneous inferring from gaze direction, deception, understanding metaphor, sarcasm and irony, pragmatics, imagination, correlation with real-life social skills, etc. It is the cognitive skill usually found in typical children by the age of four or five years old. There is a deep relation between linguistic development and ToM (Tomasello \& Farrar, 1986).

Autistic children and children with Down syndrome have been shown to have difficulties in the appreciation of certain facial, bodily, and vocal expressions of feeling status (Hobson, 1986). According to DSM-IV, the definition of Autism is: "Children and youth identified as pervasive developmental disorders are characterized by severe and pervasive impairment in several areas of development: reciprocal social interaction skills, communication skills, or the presence of stereotyped behavior interest, and activities" (DSM-IV-TR manual, 2000). According to the 'function' of autistic children, there are two kinds of autism. It is called the alternative classification of autism. They are- High Functioning Autism and Low Functioning Autism.

In High Functioning Autism, in most of the cases, the children have speech. Though, they also can have neologism and echolalia. Their IQ level is 70 or more. They have some social difficulties. They may have some problems in processing physical sensations. In this research, Theory of Mind difficulties is being tried to find out in Bengali High Functioning Autistic Children and its impact on their everyday language as well as communication. The present study is an infliction of Baron-Cohen, Leslie, and Frith's (1985) experiments on Bengali children with High Functioning Autism.

Bangladesh is a developing country in South Asia. Though awareness has increased in many ways about Autism and other mental or physical deficits, it's not enough for the overall continuing development of an autistic individual. The amount of the research on this sector are also very less in number in this country. A different autistic individual may have different types of problems in language, social behavior, and communication. In this research, the problems of autistic children are tried to be found out with very fruitful experiments. The results may help to understand their problems more specifically. Not only that, the teachers and caregivers can take help from this research to make therapy modules.

\section{LITERATURE REVIEW}

Several works have been done in past to understand the 'Theory of Mind'. The journey has not been stopped yet. The very first approach of finding the answer to 'mental state' was started by David Premack and Guy Woodruff's work. The name of their research paper is 'Does the chimpanzee have a theory of mind' (1978a). They got the inspiration behind writing this paper from Kohler (1925). In their paper, the ability to impute mental states to the self and others was given a name, 'Theory of Mind'. It is most often described as, "the ability to put oneself in someone else's shoes and usually develops in typical children by four or five years old." A system of the interface of this kind is properly viewed as a theory because such states are directly not observable, and the system can be used to make predictions about the behavior of others (Premack and Woodruff, 1978b). In their experiment, 
they showed an adult chimpanzee a series of videotape scenes of a human who was acting as struggling with some -problems such as trying to get bananas from a place, trying to escape from a locked cage, etc. For every single videotape, the chimpanzee was given several photographs. It could relate every photo with several video graphs such as a photograph of a key for the locked-up actor, a lit wick for the malfunctioning beater, etc.

Dr. Alan Leslie (1987a), in his paper, 'Pretense and Representation: The Origins of Theory of Mind', examined the ability of infants to pretend and still manage to avoid the contradictions with reality as the infant dealt with pretend. $\mathrm{He}$ presents the idea of primary representations, our ideas that represent the realities of our world. For a child to pretend, the example used in the paper is to have a child pretend that a banana is a telephone, the child needs to decouple from the primary representation and form a secondary representation that's not necessarily in line with reality, a representation of representation or a metarepresentation. This secondary representation doesn't reflect the real world as the primary does, it is not veridical as a banana is certainly not a phone.

It shows that the holder can suspend the primary representation, quarantining it, and use this secondary representation for the pretend play. Leslie states that when one thinks of representation in terms of mental states, people's beliefs, and desires, they need to deploy meta- representations because reality may or may not be in use. The example used is, 'John believes it's raining and jumps into a shop doorway because he doesn't want to get wet.' It doesn't matter if it's raining or not, John believed it was and this belief dedicated his actions. Leslie posits that a secondary representation must be at play here for us to consider this situation properly and that to use this 'opaque' logic to impute actions is to employ ToM. He believes that, pretend play is the beginning of ToM as both participants in a banana phone game are sharing the pretense that the banana is a phone. A child understands that another is representing the banana as a phone for the game just like they are, and therefore have some insights as to what the other child is thinking. Leslie states that an example of complex reasoning across meta representational structures is the ability of a child to predict the behavior of someone who holds a false belief (FB) (Leslie, 1987b). From his experiment, the false belief test is considered a milestone in identifying ToM.

In the $18^{\text {th }}$ century, scholars found a correlation between the Theory of Mind and Developmental Language Disorder (DLD). Autism is considered the most severe neurodevelopmental disorder. Some people with autism lack almost all signs of a Theory of mind. One might think of extreme cases as a form of 'mind blindness' (Baron-Cohen 1995). The researchers took different types of stimuli in their research. They tried to discover if ToM was deficient in cases of autism and if it was, to show that it was a phenomenon that was specific to autism and independent of mental retardation. The hypothesis held by the researchers was that, children with autism could not create and use secondary representation and that this deficit was not due to mental retardation but to an as yet undetermined deficit a ToM mechanism unique to autism.

Another fruitful experiment appeared in 1989 with the 'smarties' test. In this experiment, a child is asked what will appear in a box clearly labeled 'smarties' (Perner, Frith, Leslie, \& Leekam, 1989). Once the box is opened it is revealed that the box is full of pencils. The child is then asked two belief questions. What do they think was in the box before it was opened, to which the typical child answers 'smarties', and what will the next child walk in the room think is in the box? The answers given by a normal child with typical ToM will also be 'smarties. When this test was administrated to autistic children they replied 'pencils' to both questions, reflecting the reality as they knew it at that time and not their previous false belief or the false belief of the next child that would walk into the room.

The neurobiology of the Theory of mind was a crucial issue of discussion in the 19th century. Several neurobiological models have been proposed as bases for ToM (Akel, 2003). There is a plethora of studies that have investigated the involvement of brain areas during simple and complex forms of metallization. Various brain regions can be classified into three main groups:

- Brain areas are solely involved in the representation of self-mental states.

- Brain areas are solely involved in the representation of the mental state of others.

- Brain areas that are common to both

The parts which are engaged in different functions of Theory of Mind are-

- Inferior parietal lobe.

- Superior temporal sulcus, orbitofrontal cortex.

- Inferolateral frontal cortex.

- Limbic and Paralympic regions.

The parts of the brain as well as seemingly independent areas are functionally interconnected circuits that are involved in different responses and representations of the Theory of Mind. Russell et al. (2000) showed that during a mental attribution task Broadmann's area 44/45/47 is involved. Scholars opined about mirror neurons- a group of cells that are involved in the mental attribution process. Information in the brain is often fed forward from posterior to anterior regions through limbic and paralimbic structures.

In Bangladesh, some works have been done on relating linguistics and the Theory of Mind. The very fast and mentionable research has been done in the sector which is about the false belief of Bengali autistic children (Nasrin, 2018a). In this research, 10 autistic children (6 high functioning, 4 low functioning) have been taken as participants. They were shown some fruits and vegetables made of mud and were asked two questions - 'what are the name of these' and 'are they real?' They were showed pictures of different emotions and also asked several questions 
which can represent their theory of mind. In the research, the fact gets highlighted that autistic children can only acquire the knowledge of iconic signs and faces difficulty in acquiring the knowledge of symbolic signs.

In 2019, an important paper on this sector was published by Morton Ann Gernsbacher and Melanie Yergeau. This article reviews empirical evidence that fails to support the claim that autistic people are uniquely impaired, much less that all autistic people are universally impaired. In their article, they have demonstrated how the claim that autistic people lack a theory of mind fails empirically; it fails in its specificity, universality, replicability, convergent validity, and predictive validity. Despite these numerous empirical failures, the claim pervades psychology and well beyond (Gernsbacher \& Yergeau, 2019).

A very recent study on this topic has been done by Rosello et. al in 2020. In their research, they tried to identify profiles of children with ASD without intellectual disability based on explicit and applied ToM knowledge. They also compared the results with a group of Typically Developed Children. They have experimented with the "vocabulary test" and "memory test". The research sums up the result as the two groups with ASD had more difficulties than the TD group in understanding basic emotions, distinguishing between the physical and mental, making second-order inferences, or making complex social judgments. (Rosello et. al,2020). In recent years, multidisciplinary approaches are using to do research on ToM as well as its relation with Autism and other neurodevelopmental disorders.

\section{METHOD}

In this research qualitative method has been inflicted to collect data. Collected data have been arranged and showed with charts and graphs. Data have been collected from a famous Autistic specialized school naming Autism Welfare Foundation (AWF), Dhaka, Bangladesh.

\section{- Research Questions:}

1. What types of Theory of Mind deficits can be present in an autistic individual?

2. How does Theory of Mind deficits hinder successful communication?

\section{Participants}

There is a total of 08 participants with High Functioning Autistic children in this research. The participants are diagnosed according to established criteria They have been chosen by purposive sampling. By purposive sampling, the researcher gave importance to the aim of the research. Time and other elements were also in consideration. Before data collection, 03 days observations have been done. The researcher went to their classroom, music room, dance room, assembly. She also discussed about the children with their teacher and caregivers, checked their database from the record book. There are some exclusion and inclusion criteria for choosing the participants. The inclusion criteria are:
- Who are going through regular schooling process.

- Whose IQ are greater than 70 .

- Whose chronological age is 16-22. Their mental age assisted by their own institution is 8-12.

- Have speech.

- Who are skilled in social interaction

The exclusion criteria is - the participants are not been chosen maintaining the ratio of boys and girls.

\section{- Experiments}

3 types of tests have been done to collect data. They are;

1. Picture Test

2. First Order False Belief Test

3. Symbolic play Test

Picture test is much known test in this sector. Before this study, many researches did this test. They found is very fruitful. Ten (10) different types of emotion to know their ability to understand emotional words. This test helps to know their ability to perceive the things and emotions they find in their real life. There are some other pictures where there is a secondary meaning of things. They are used to know their understanding of symbolic meaning instead of iconic meaning. Again, there are some pictures of nonverbal communication; which help to examine their ability to understand different kind of nonverbal sign.

First order false belief test is another popular test in the sector. It measures a child's understanding of the fact that, different people can have different thoughts about the same situation. They are called first -order tests because they involve inferring only one person's mental states.

In $3^{\text {rd }}$ test, the term 'symbol' is very important. Symbol is something-stands for, represents or denotes something else, not by exact resemblance, but by vague suggestion or by some accident or conventional relation (Ricks \& Wing, 1975). This experiment helps to find out different kinds of cognitive ability at the same time.

\section{DATA REPRESENTATION}

The responses of the participants of three different stimuli are shown in different chart here. Here the identification of the participants is their $1^{\text {st }} 2$ letters of name. The positive and right response are identified by $(\sqrt{ })$ mark and the irrelevant, wrong or no response are shown by $(\mathrm{x})$ mark.

\section{- Representation of Experiment One- Picture Test (Appendix 04)}

In this test, 10 pictures were shown to the participants. They are -

1. A baby is crying

2. A sad-faced baby

3. A girl is laughing

4. An afraid girl

5. A mother adoring her child in her lap 
6. A couple is quarreling with each other

7. A teacher is giving punishment to her students

8. A picture of a classroom where the teacher is talking with her students

9. A happy photo of players after winning the cricket match
10. A boy is thinking about something

The ten pictures are very much related to their everyday life. There are five single emotional pictures and other 5 pictures are more contextual and symbolic. The representations are showed in the table below-

Table 01: Responses of HFA Children in Picture Test

\begin{tabular}{|c|c|c|c|c|c|c|c|c|c|c|}
\hline Participant & $\mathbf{1}$ & $\mathbf{2}$ & $\mathbf{3}$ & $\mathbf{4}$ & $\mathbf{5}$ & $\mathbf{6}$ & $\mathbf{7}$ & $\mathbf{8}$ & $\mathbf{9}$ & $\mathbf{1 0}$ \\
\hline $\mathrm{MA}_{1}$ & $\sqrt{ }$ & $\sqrt{ }$ & $\sqrt{ }$ & $\sqrt{ }$ & $\sqrt{ }$ & $\sqrt{ }$ & $\sqrt{ }$ & $\sqrt{ }$ & $\sqrt{ }$ & $\sqrt{ }$ \\
\hline $\mathrm{MA}_{2}$ & $\sqrt{ }$ & $\mathrm{x}$ & $\sqrt{ }$ & $\mathrm{x}$ & $\mathrm{x}$ & $\sqrt{ }$ & $\mathrm{x}$ & $\sqrt{ }$ & $\mathrm{x}$ & $\mathrm{x}$ \\
\hline $\mathrm{PO}$ & $\sqrt{ }$ & $\sqrt{ }$ & $\sqrt{ }$ & $\sqrt{ }$ & $\sqrt{ }$ & $\sqrt{ }$ & $\sqrt{ }$ & $\sqrt{ }$ & $\sqrt{ }$ & $\sqrt{ }$ \\
\hline $\mathrm{SH}$ & $\sqrt{ }$ & $\mathrm{x}$ & $\sqrt{ }$ & $\mathrm{x}$ & $\mathrm{x}$ & $\mathrm{x}$ & $\sqrt{ }$ & $\mathrm{x}$ & $\mathrm{x}$ & $\mathrm{x}$ \\
\hline $\mathrm{AB}$ & $\sqrt{ }$ & $\mathrm{x}$ & $\sqrt{ }$ & $\mathrm{x}$ & $\sqrt{ }$ & $\sqrt{ }$ & $\mathrm{x}$ & $\sqrt{ }$ & $\mathrm{x}$ & $\mathrm{x}$ \\
\hline $\mathrm{SR}$ & $\sqrt{ }$ & $\mathrm{x}$ & $\sqrt{ }$ & $\sqrt{ }$ & $\mathrm{x}$ & $\mathrm{x}$ & $\mathrm{x}$ & $\mathrm{x}$ & $\mathrm{x}$ & $\mathrm{x}$ \\
\hline $\mathrm{AN}$ & $\sqrt{ }$ & $\sqrt{ }$ & $\sqrt{ }$ & $\sqrt{ }$ & $\mathrm{x}$ & $\sqrt{ }$ & $\mathrm{x}$ & $\mathrm{x}$ & $\mathrm{x}$ & $\mathrm{x}$ \\
\hline $\mathrm{AS}$ & $\sqrt{ }$ & $\sqrt{ }$ & $\mathrm{x}$ & $\mathrm{x}$ & $\sqrt{ }$ & $\mathrm{x}$ & $\sqrt{ }$ & $\sqrt{ }$ & $\mathrm{x}$ & $\mathrm{x}$ \\
\hline
\end{tabular}

\section{Representation of Experiment Two-False Believe Test}

In this test, there are two questions. First one is 'What is this'. The participants are able to response correct in this question but when they were asked, 'is it real or false', they didn't answer correctly.
The responses of the different shapes of candles have been shown by $(\sqrt{ })$ and $(\mathrm{x})$ marks. As there were 2 parts in the test, the first responses were for $1^{\text {st }}$ question - what is this and the $2^{\text {nd }}$ responses were for $2^{\text {nd }}$ question (is it real or false).

Table 02: Responses of HFA Children in False Belief Test

\begin{tabular}{|c|c|c|c|c|}
\hline Participant & Love Shape & Star Shape & Fish Shape & Flower Shape \\
\hline $\mathrm{MA}_{1}$ & $\sqrt{ } / \sqrt{ }$ & $\sqrt{ } / \sqrt{ }$ & $\sqrt{ } / \sqrt{ }$ & $\sqrt{ } / \sqrt{ }$ \\
\hline $\mathrm{MA}_{2}$ & $\sqrt{ } / x$ & $\sqrt{ } / x$ & $\sqrt{ } / x$ & $\sqrt{ } / x$ \\
\hline $\mathrm{PO}$ & $\sqrt{ } / \sqrt{ }$ & $\sqrt{ } / \sqrt{ }$ & $\sqrt{ } / \sqrt{ }$ & $\sqrt{ } / \sqrt{ }$ \\
\hline $\mathrm{SH}$ & $\mathrm{x} / \sqrt{ }$ & $\sqrt{ } / \sqrt{ }$ & $\sqrt{ } / \sqrt{ }$ & $\mathrm{x} / \sqrt{ }$ \\
\hline $\mathrm{AB}$ & $\mathrm{x} / \mathrm{x}$ & $\sqrt{ } / x$ & $\mathrm{x} / \mathrm{x}$ & $\mathrm{x} / \sqrt{ }$ \\
\hline SR & $\sqrt{ } / \sqrt{ }$ & $\sqrt{ } / \sqrt{ }$ & $\sqrt{ } / \sqrt{ }$ & $\mathrm{x} / \sqrt{ }$ \\
\hline AN & $\sqrt{ } / x$ & $\sqrt{ } / x$ & $\sqrt{ } / x$ & $\mathrm{x} / \mathrm{x}$ \\
\hline AS & $\sqrt{ } / x$ & $\mathrm{x} / \mathrm{x}$ & $\mathrm{x} / \mathrm{x}$ & $\sqrt{ } / x$ \\
\hline
\end{tabular}

\section{Representation of Experiment Three-Symbolic Play Test}

This is the hardest test for the High Functioning Autistic children. In every stimulus, there are four parts. They are- sensory motor, ordering, functional and pretending. The responses of HFA children are given below:

Table 03: Responses of HFA Children in Symbolic Play Test

\begin{tabular}{|c|c|c|c|c|c|c|c|c|c|c|c|c|c|c|c|c|}
\hline \multirow{2}{*}{ Participant } & \multicolumn{4}{|c|}{ Elephant } & \multicolumn{4}{|c|}{ Horse } & \multicolumn{4}{|c|}{ Tiger } & \multicolumn{4}{|c|}{ Lion } \\
\hline & $\Rightarrow \rightarrow$ & 0 & $-\cdots$ & - & $=>$ & $0:$ & $\omega$ & $0-0$ & $\therefore>$ & $0:$ & $-\cdots$ & $0-0$ & $\Rightarrow$ & 0 & - & $0-0$ \\
\hline $\mathrm{MA}_{1}$ & $\sqrt{ }$ & $\mathrm{x}$ & $\sqrt{ }$ & $\sqrt{ }$ & $\sqrt{ }$ & $\mathrm{x}$ & $\sqrt{ }$ & $\sqrt{ }$ & $\sqrt{ }$ & $\mathrm{x}$ & $\sqrt{ }$ & $\sqrt{ }$ & $\sqrt{ }$ & $\mathrm{x}$ & $\sqrt{ }$ & $\sqrt{ }$ \\
\hline $\mathrm{MA}_{2}$ & $\sqrt{ }$ & $\mathrm{x}$ & $\sqrt{ }$ & $\sqrt{ }$ & $\sqrt{ }$ & $\mathrm{x}$ & $\sqrt{ }$ & $\sqrt{ }$ & $\sqrt{ }$ & $\mathrm{x}$ & $\sqrt{ }$ & $\sqrt{ }$ & $\sqrt{ }$ & $\mathrm{x}$ & $\sqrt{ }$ & $\sqrt{ }$ \\
\hline $\mathrm{PO}$ & $\sqrt{ }$ & $\sqrt{ }$ & $\sqrt{ }$ & $\sqrt{ }$ & $\sqrt{ }$ & $\sqrt{ }$ & $\sqrt{ }$ & $\sqrt{ }$ & $\sqrt{ }$ & $\mathrm{x}$ & $\sqrt{ }$ & $\mathrm{x}$ & $\sqrt{ }$ & $\sqrt{ }$ & $\sqrt{ }$ & $\mathrm{x}$ \\
\hline $\mathrm{SH}$ & $\sqrt{ }$ & $\mathrm{x}$ & $\sqrt{ }$ & $\mathrm{x}$ & $\sqrt{ }$ & $\mathrm{x}$ & $\sqrt{ }$ & $\mathrm{x}$ & $\sqrt{ }$ & $\mathrm{x}$ & $\sqrt{ }$ & $\mathrm{x}$ & $\sqrt{ }$ & $\mathrm{x}$ & $\sqrt{ }$ & $\mathrm{x}$ \\
\hline
\end{tabular}




\begin{tabular}{|c|c|c|c|c|c|c|c|c|c|c|c|c|c|c|c|c|}
\hline $\mathrm{AB}$ & $\mathrm{x}$ & $\mathrm{x}$ & $\sqrt{ }$ & $\mathrm{x}$ & $\mathrm{x}$ & $\mathrm{x}$ & $\sqrt{ }$ & $\mathrm{x}$ & $\mathrm{x}$ & $\mathrm{x}$ & $\sqrt{ }$ & $\mathrm{x}$ & $\mathrm{x}$ & $\mathrm{x}$ & $\sqrt{ }$ & $\mathrm{x}$ \\
\hline $\mathrm{SR}$ & $\sqrt{ }$ & $\mathrm{x}$ & $\sqrt{ }$ & $\mathrm{x}$ & $\sqrt{ }$ & $\mathrm{x}$ & $\sqrt{ }$ & $\mathrm{x}$ & $\sqrt{ }$ & $\mathrm{x}$ & $\sqrt{ }$ & $\mathrm{x}$ & $\sqrt{ }$ & $\mathrm{x}$ & $\sqrt{ }$ & $\mathrm{x}$ \\
\hline $\mathrm{AN}$ & $\sqrt{ }$ & $\mathrm{x}$ & $\sqrt{ }$ & $\sqrt{ }$ & $\sqrt{ }$ & $\mathrm{x}$ & $\sqrt{ }$ & $\sqrt{ }$ & $\sqrt{ }$ & $\mathrm{x}$ & $\sqrt{ }$ & $\sqrt{ }$ & $\sqrt{ }$ & $\mathrm{x}$ & $\sqrt{ }$ & $\mathrm{x}$ \\
\hline $\mathrm{AS}$ & $\mathrm{x}$ & $\mathrm{x}$ & $\sqrt{ }$ & $\sqrt{ }$ & $\mathrm{x}$ & $\mathrm{x}$ & $\sqrt{ }$ & $\mathrm{x}$ & $\mathrm{x}$ & $\mathrm{x}$ & $\sqrt{ }$ & $\sqrt{ }$ & $\mathrm{x}$ & $\mathrm{x}$ & $\sqrt{ }$ & $\sqrt{ }$ \\
\hline
\end{tabular}

\section{RESULT}

\section{- Analysis of Responses of HFA Children in Picture Test}

The first participant can response every question and could give correct answer. The $2^{\text {nd }}$ participant can answer correctly in 4 questions. The participant does not response in the picture in stimuli 2. The participant answered, 'cinta kore' (thinks) [See Appendix -4] that means he knows the gesture of 'thinking'. But if he understands that face of the boy represents the mental state of sad; he can properly answer it. In stimuli 4 , he uses a phrase according to iconic meaning [See Appendix-4]. That means he can interpret the iconic meaning. But cannot understand the 'fear' and 'anxiousness' in the eyes. $\mathrm{He}$ also replies with icon in the stimuli $9 . \mathrm{He}$ replied, "hat" (hand). The $3^{\text {rd }}$ participant can response all stimuli correctly. The $4^{\text {th }}$ participants given data is much interesting. In $2^{\text {nd }}$ stimuli, he replied, "haci dei”; (sneeze); that means he could not differentiate the nonverbal sign between sneezing and sadness. In the $4^{\text {th }}$ stimuli. The participant answers ironically as 'kane hat d ie rak ${ }^{\mathrm{h}} \mathrm{e}$ ' (keep hands on the ear). In the $5^{\text {th }}$ stimuli the participant replies 'matha batha' (headache); but when he is asked 'whose', he does not response anything. But by his response it is clear that he knows what to do at the time of headache. In $6^{\text {th }}$ stimuli, he replied 'dariye thake' (standing). The other things can't be focused by him. In the picture of classroom, he says, 'cupcap (silent). He cannot identify that, it is a picture of a classroom. In the picture of enjoying together after winning the match, he says, "children are learning cricket". That means he knows about the dress of cricket. Though there is no bat or ball in the hand of the players, he can understand the context by watching dress and field. In the last stimuli he replied 'golpo bola;' (telling story) though there is no other speaker or listener in the picture. There can be a fact that he has an experience about 'story telling' when he or other listener uses this gesture (keeping hands on the cheek).

The $5^{\text {th }}$ participant repeats a phrase twitch. It has been known from the caregiver of the school that he cries a lot in the school. It can be reason of his such response. He does not response anything in $7^{\text {th }}$ and $8^{\text {th }}$ stimuli. In the last stimuli he replies, 'a:dər kərəchhe' (cuddle up) which has no relation to the content. The $6^{\text {th }}$ participant can answer 3 questions perfectly. He didn't response in one stimulus- the picture of a classroom. In $2^{\text {nd }}$ stimuli he said about some icon. He did the same thing with the following stimuli. In $6^{\text {th }}$ stimuli he focused on only fingers. In $7^{\text {th }}$ and $8^{\text {th }}$ stimuli he responded with only literal meaning. In $9^{\text {th }}$ stimuli he didn't understand the contextual meaning. The $7^{\text {th }}$ participant could correctly response in 6 pictures. In $5^{\text {th }}$, 8th and $10^{\text {th }}$ picture, he didn't response anything. In the $7^{\text {th }}$ stimuli, what was about giving punishment to students, he replied 'lopa mis amake boka dise' (Lopa miss has scolded me) [see Appendix- 4]. He was talking about his class teacher, who scolds the participant that morning for sleeping in the class. The $8^{\text {th }}$ participant can answer 5 questions correctly. He does not response in 4 questions. In $10^{\text {th }}$ stimuli he just says 'babu' (baby). No other thing is focused by him. The responses of 10 pictures are shown in the graph below:

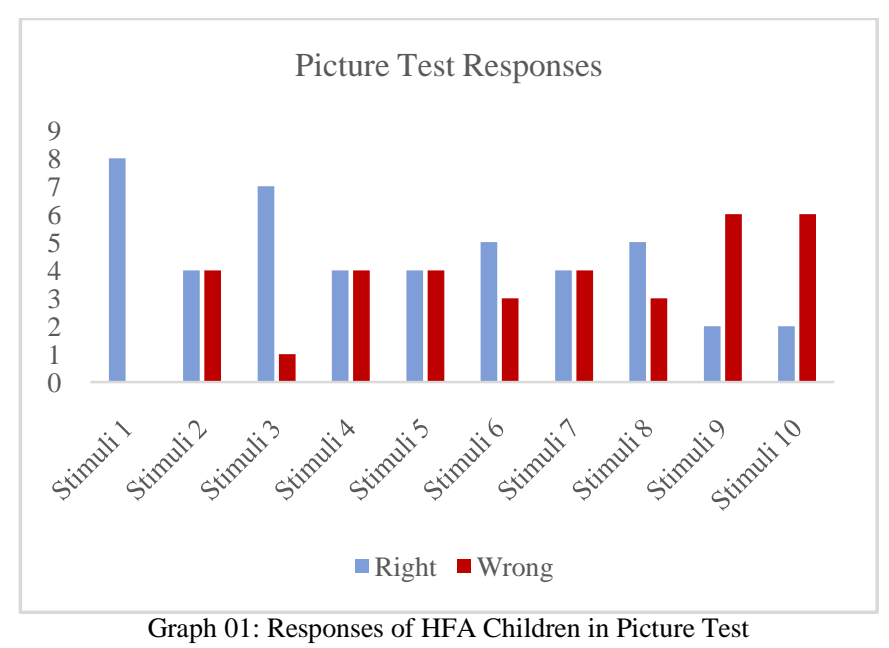

So, it is clear that the participants can response in stimuli 1,3 best. The worst performance is in stimuli 9 and 10. As there are two types of picture, the graph shows that the participants show more skill in identifying only nonverbal sign related pictures more than the pictures with contextual meaning.

- Analysis of the Responses of HFA Children in False Belief Test

The participant shows best responses in identifying 'Shape of the star'. Seven of total eight participants can answer the question properly. Then the shape of 'Love' and 'Fish' are identified by six participants. The $1^{\text {st }}$ and $3^{\text {rd }}$ participants answer 4 questions properly. The $2^{\text {nd }}$ participant shows good performance in responding $1^{\text {st }}$ question but cannot answer properly in $2^{\text {nd }}$ question. The participants show comparatively poor performance in identifying the shape of 'Flower'. In $2^{\text {nd }}$ question, every candle has been given to their hand and have been asked if these are real or false. But they give different answer for different shape. Such as the 'Star' is false but the 'Fish' is real. All of them can respond with their English name such as- love, fish, flower and star. There 2 graphs are shown to represent the responses of $1^{\text {st }}$ and $2^{\text {nd }}$ question. The $1^{\text {st }}$ graph represents the responses of $1^{\text {st }}$ question. 


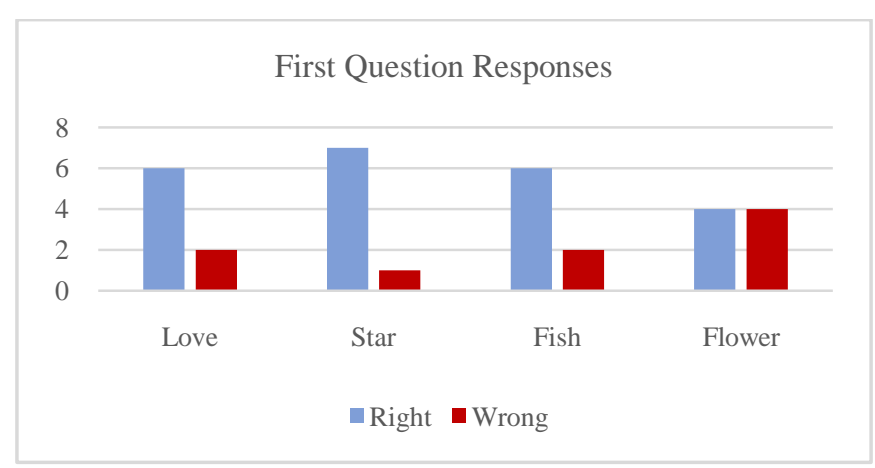

Graph 02: First Question Responses of HFA Children in False Belief Test

The graph represents that, the participant showed best performance in identifying $2^{\text {nd }}$ stimuli- 'Star Shape'. The second-best responses were in 'Fish Shape'. They show poor performance in identifying flower shape. This following graph represents the responses of $2^{\text {nd }}$ question- is it real or false.

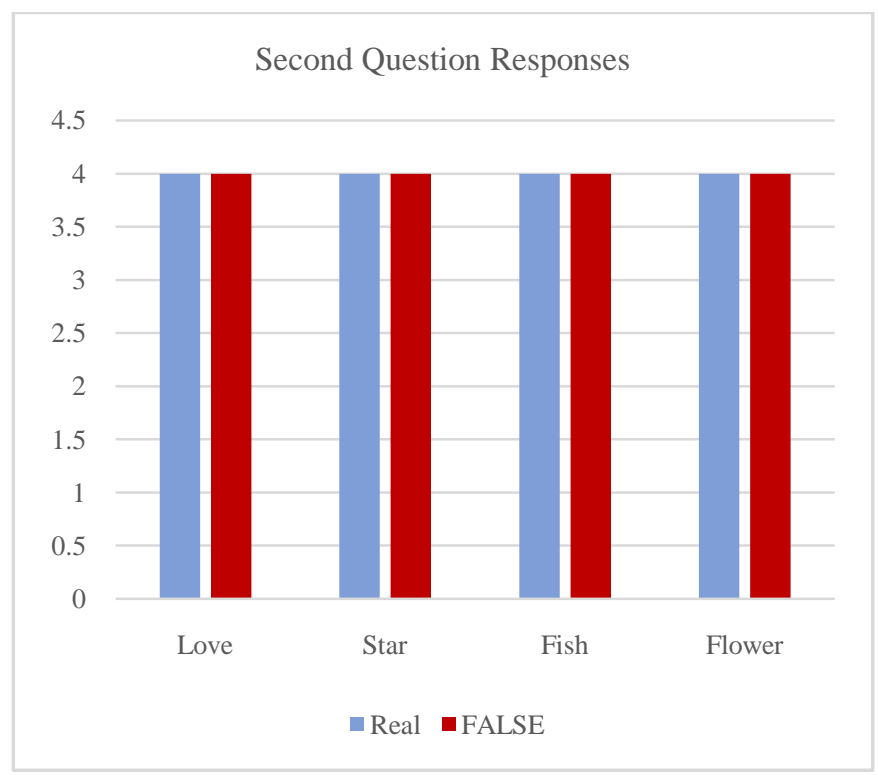

Graph 03: Second Question Responses of HFA Children in False Belief Test

We can see that the responses of right or wrong is $4: 4$. Though they have experience of making different shapes of candle in their workshop, they have not shown good performance in identifying the 'reality' of different shapes.

- Analysis of the Responses of HFA Children in Symbolic Play Test

Baron-Cohen (1987) gave an account of description of categories of symbolic play. Such as:

1. Sensorimotor: Banging, weaving, sucking, throwing, rolling, twiddling or sniffing objects, with no attention paid to their function.

2. Ordering: A more intelligent behavior involving the child imposing some pattern onto the objects, such as lining them up, pilling them up, putting one inside another, arranging them in systematic ways, but still with no regard for their function.
3. Functional Play: Using the objects appropriately, that is according to their intended function.

4. Pretend Play: Child usage and object as if it is another object, or attribute properties to an object which it does not have, or refers to absent object as if they were present.

In sensory motor activity, the participants touch and wave the items [See appendix 5]. Only 1 participant does not do any sensory motor activity. In the part of ordering, only 1 participant lines up elephant, horse, and lion together. Other persons did not show any performance in this part. In functional section, the performances are best. $1^{\text {st }}, 3^{\text {rd }}, 4^{\text {th }}, 6^{\text {th }}$, $7^{\text {th }}$ and $8^{\text {th }}$ participant answers with the 'Bengali name' of the animals. Other four participants respond with the English name of the animals. In the pretend part, participants can just imitate the noise of the animals. The $1^{\text {st }}$ performer can make the noises of 4 animals. Though they are not fully perfect. The $2^{\text {nd }}$ participant also does that. The $3^{\text {rd }}$ participant can imitate the noise of elephant and horse. He does not response in pretending tiger and lion. The $4^{\text {th }}$ participant cannot make any noise of the animals. The $5^{\text {th }}$ and $6^{\text {th }}$ participant showed same performance like the $4^{\text {th }}$. The $7^{\text {th }}$ participant can answer pretending first 3 stimuli. The $8^{\text {th }}$ participant can pretend the noise of elephant, tiger and lion. He cannot imitate the noise of horse. The participants show best performance in identifying the name of the animals. Some of the participants show good performance in pretending.

\section{DISCUSSION}

A child acquires knowledge of different things by experience. These experiences are achieved by five organs. By the growth of age, a child can improve his knowledge of imposing logic behind reasons, knowledge of abstract thinking, and knowledge of applying his own decision with logic. He develops his social norms and values. To express knowledge, a child takes the help of language. So, the Theory of Mind is deeply interconnected with language. The interface between language and the Theory of Mind is bidirectional (Schick, Villiers, Villiers \& Hoffmeister, 2007). In children with neurodevelopmental disorder, the development of "knowledge is not the same. That is a reason for their not responding or wrong responses to the stimulus in this research.

The skill of spontaneous descriptions of dual identity grows up by a child's development of the Theory of Mind. Another cornerstone of the normal child's Theory of Mind is an understanding of where knowledge comes from so that the child can work out who knows what, and more importantly, who does not know what. This is a key development simply because it underpins appropriate communication. Normal developing children can pick out words from a wordlist that refer to what goes on in the mind or what the mind can do. But in the case of autistic children, the thing is different. They face difficulties in choosing appropriate words according to the context of the situation. Understanding metaphor, sarcasm, and irony are other concerns of the Theory of Mind. A child with autism cannot use them in communication. 
Nonverbal communication is a very important part of the language. Gesture, posture, gaze direction, head movement, etc. are very important in communication. With the development of the Theory of Mind, a child can develop these skills. All in all, a child with deficits in the Theory of Mind faces many problems in producing and comprehending language. After analyzing data, the results indicate the following deficits:

Not Understanding Contextual Meaning: A child can develop these linguistic elements by Theory of Mind. There are 2 types of meaning of things. They are -

\section{Denotative meaning: Primary meaning/ Dictionary meaning.}

II. Connotative meaning: The second meaning involves many things.

This thing can be correlated with the development of the Theory of Mind because a child knows about the denotative meaning of things first. After the development of his age, he acquires knowledge of connotative meaning. If a child can acquire knowledge about the real meaning of things we can say that his Theory of Mind is developed. A child with High Functioning Autism most of the time fails to understand the connotative meaning of things. If we see, semantically, language is a collection of signs which is used in a specific community or group.

There are 2 types of signs that can be mentioned here. They are -

\section{Iconic Sign}

\section{Symbolic Sign}

A child can develop the knowledge of symbolic signs by their environment and culture. In that case, the Theory of Mind plays a vital role. Children with High Functioning Autism showed difficulties in understanding the contextual meaning of the picture test. They see only 'objects' or 'icons. They can't correlate the objects to make an overall meaning. They don't try to understand the context, rather they try to find meaning in a literal way. It hampers their understanding of other's language. So, communication hampers a lot.

\section{- $\quad$ Bring to Bear the Experience}

'Experience' is very important in these children's behavior. As they have problems in their long-time memory, they practice some behavior, norm, etc. regularly. In a new context, if they find anything related to the experience they try to relate it. But most of the time they fail to impose it correctly. Because they have a problem in syntactic level and pragmatics. To make it clearer, a participant's response can be mentioned here. In the picture of a couple is quarreling a participant answered, 'father' [See appendix 4]. That means he has an experience of seeing his father in that way. But it is not his father and the context of the picture is "conjugal muss", the children can't identify it. So, he cannot represent it verbally. This kind of deficit hampers their communication.

\section{- Understanding Own Mental State}

Autistic children have much more difficulty in making the judgment of using mental states words (Baron-Cohen \& Ring, 1994). Children with High Functioning Autism have a problem in understanding mental states. They somehow understand their mental state. For example- he is happy or he is sad. But the same situation can be present in others- they cannot understand it. So, if they find someone crying, he thinks 'he is crying', that's why in many questions they respond as their states. For example, a participant responds to only one-word phrase in 3 questions [See appendix -4]. He replied, "crying" in every answer proves that he was more concentrated on his mental state. As a child with High Functioning Autism has a problem in understanding their mental state, he cannot be part of any continuous communication. Not only that, he cannot condole anyone.

\section{- Problem of Focusing}

Normal people cognitively see their surroundings. His understanding of what should be focused or what should not be; is determined by himself. Many factors work behind this. But in children with High Functioning Autism, it is unknown and unsure which object they will focus on or on which they won't. In the picture test, High Functioning Autistic children responded in a picture of 'quarreling' as- 'finger' [See appendix-4]. That means he just focused on it. No other objects are deliberated by him. It hampers their communication.

\section{- $\quad$ Not Understanding False Belief}

In this research, things which are used by them in their everyday life, such stimuli have been selected for the experiment. Before these experiments, a false belief test has been done with Bengali HFA and LFA children with 4 pieces of soil-made vegetables (Nasrin, 2018b). In that experiment, High Functioning Autistic children have shown better performance than children with Low Functioning Autism. Though they can understand the shapes of the candle, in identifying their 'reality they have shown poor performance. Another surprising fact is that, though all of the participants have touched the candles, they cannot respond same things for all items. Such as, they have identified the star was false but the flower was real. In real life, this problem causes many communication gaps.

\section{- Problem in Perception}

The process of perception has several stages. It starts with sensation, when we perceive (see, hear, feel, etc.) the objects; then the incoming information passes through special areas in the brain and the sensory perceptions are interpreted (percept or mental image is created) and then joined with appropriate cognitive associations (concept - the idea of a class of objects/ general notion-is formed) (Bogdashina, 2005). Children with High Functioning Autism have problems in perception. They have been showing different types of problems in perception 
in the different stimuli. It causes different types of communication gaps in real life.

\section{- $\quad$ The tendency of Making Non-words}

Children with High Functioning Autism tend to make nonwords. They are not because of neologism rather they utter them whenever they want. It causes a serious communication gap. They cannot make understand what they want or want to do.

\section{CONCLUSION}

The theory of mind comes from our ability to use language. A language is an important tool for the whole communication system. Not only language but a comprehensive idea about the overall development of a child is also obtained through the development of his Theory of mind. Now a days, in most of the developed countries, training programs or sessions on the development of various theories of mind are organized for typically developed children. In that case, it is a must to arrange training programs like this for children with any neurodevelopmental disabilities, including autism.

The concept of Theory of Mind is very new in the context of our country. At present, various specialized schools for autistic children have been set up in different places of the country. Doing this research can benefit the people involved in this type of work. Since ToM deficits of autistic children are represented here in different ways by different materials, these results can be related to their schooling. In addition, different autistic children may have different deficiencies. If the authority has a clear idea about ToM deficits, the Therapy Modules will also be more effective. If any researcher wants to do more detailed research on Bengali autistic children later, this research may be good source of secondary data.

This research can make anyone aware, including the parents of an autistic child. Which behaviors cannot be done in front of the child or how to deal with them, will be known through this research. Autism is not a disease. It is a neurodevelopmental disorder. It is a lifetime problem and cannot be cured fully. So, the Theory of Mind deficits also cannot be improved totally. But necessary steps can be taken to make an autistic child's life easier. All in all, this research can help to do so to the Bengali High Functioning Autistic children.

\section{REFERENCES}

[1] Abu-Akel, A. (2003). A neurobiological mapping of theory of mind. Brain Research Reviews, 43. 29-40.

[2] American Psychiatric Association. (2000). Diagnostic and statistical manual disorders -Text Revision (4 ${ }^{\text {th }}$ Eds. DSM-IV). Washington, DC: America.

[3] Baron-Cohen, S., Leslie, A. M. \& Frith, U. (1985). Does the autistic child have a "theory of Mind?" Cogitation, 21 (1), 37-46.

[4] Baron-Cohen, S., (1987). Autism and symbolic play. British Journal of Developmental Psychology, 5, 139-148.

[5] Baron-Cohen, S., \& Ring, H. (1994). A model of the mindreading system: neuropsychological and neurobiological perspective. Origins of an Understanding Mind.

[6] Baron-Cohen, S. (1995). Mindblindness: An Essay on Autism and Theory of Mind. The MIT Press.

[7] Bogdashina, O. (2005). Communication Issues in Autism and Asperger Syndrome. Do we speak the same language? London and Philadelphia: Jessica Kingsley Publishers .44

[8] Call, J \& Tomasello, M. (1998). Does the Chimapanzee have Theory of Mind: Thirty years later. Trends in Cognitive Sciences, 12 (5), 187-192.

[9] Gernsbacher, A.M. (2019). Empirical Failures of the Claim That Autistic People Lack a Theory of Mind. Archives of Scientific Psychology, 7 (1): 102-118.

[10] Hobson, R. P. (1986). The autistic child's appraisal of expressions of emotion. Journal of Child Psychology and Psychiatry. 27, 321342.

[11] Kohler, W. (1925). The Mentality of Apes.

[12] ${ }^{a}$ Leslie, A. M. (1987). Pretense and Representation: The Origins of "Theory of Mind". Psychology Review, 94(4), 412-426.

[13] 'beslie, A. M. (1987). Pretense and Representation: The Origins of "Theory of Mind". Psychology Review, 94(4), 412-426.

[14] a Nasrin, S. (2018), Monogoto Totto o Bangla Vashi Autistic Shishur 'vrantodharona Porjobekkhon dokkhota bishleshon. (An analysis of the theory of mind and ability to asses 'false belief' of Bengali children with autism). Bangladesh Asiatic Society, 36.

[15] ' Nasrin, S. (2018), Monogoto Totto o Bangla Vashi Autistic Shishur 'vrantodharona Porjobekkhon dokkhota bishleshon. (An analysis of the theory of mind and ability to asses 'false belief' of Bengali children with autism). Bangladesh Asiatic Society, 36.

[16] ${ }^{a}$ Premack, D. \& Woodruff, G. (1978). Does the chimpanzee have Theory of Mind? Behavioral and Brain Sciences, 4, 515-526.

[17] ${ }^{b}$ Premack, D. \& Woodruff, G. (1978). Does the chimpanzee have Theory of Mind? Behavioral and Brain Sciences, 4, 515-526.

[18] Ricks, D. M., \& Wing, L. (1975). Language, Communication, and the Use of Symbols in Normal and Autistic Children. Journal of Autism \& Childhood Schizophrenia, 5, 191-221.

[19] Rosello, B., Berenguer, C., Baixuali, I.,Garcia, R. \& Miranda, A. (2020). Theory of Mind Profiles in Children with Autism Spectrum Disorder: Adaptive/Social Skills and Pragmatic Competence. Front Psychol.

[20] Russell, K., Bullmore, E. T., Soni W., Suckling, J., Brammer, M.J., Simons, A., Williams, S. C. R., Sharma, T. (2000). Exploring the social brain in schizophrenia: left prefrontal underactivation during mental state attribution. Psychiatry, 157, 2040-2042.

[21] Schick, B., Villiers, p., Villiers,J., Hoffmeister,D. (2007) .Child Development 78 (2)

[22] Tomasello, M. \& Farrar, M. J. (1986). Joint attention and early language. Child Development, 57, 1454-1463. 
Appendix -1
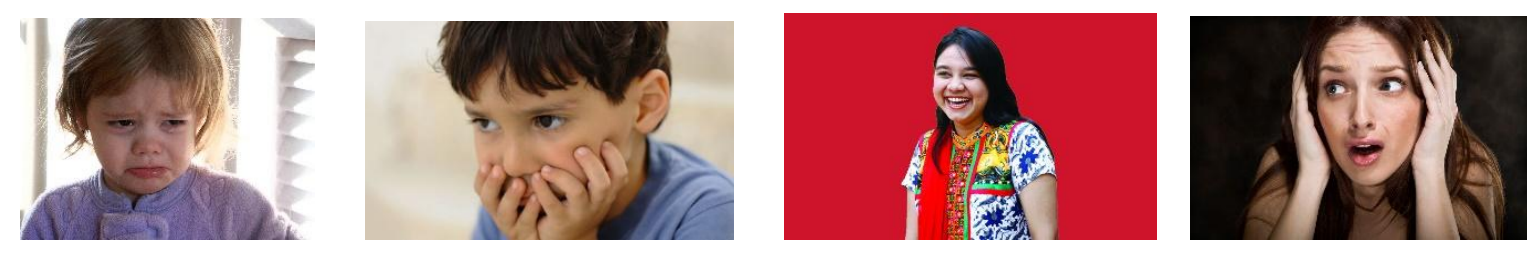

Stimuli 01

Stimuli 02

Stimuli 03
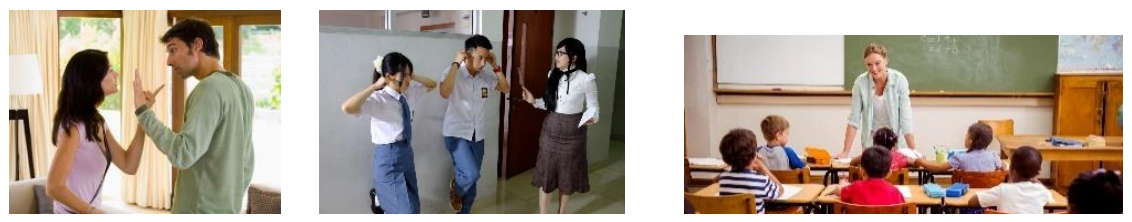

Stimuli 04

Stimuli 06

Stimuli 07

Stimuli 08

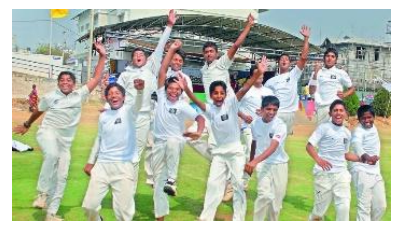

Stimuli 09

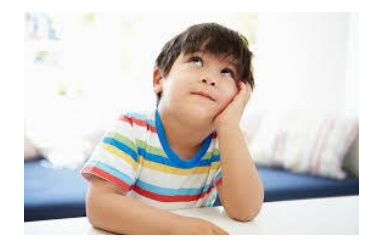

Stimuli 10

Appendix- 2

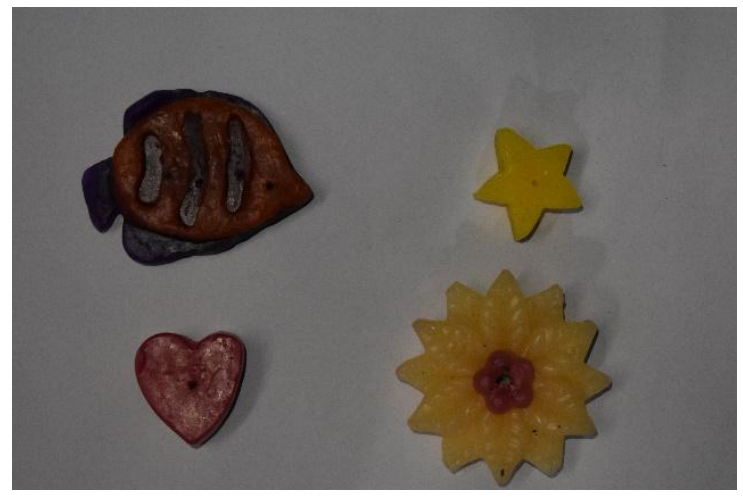

Stimuli for Experiment 02 


\section{Appendix- 3}
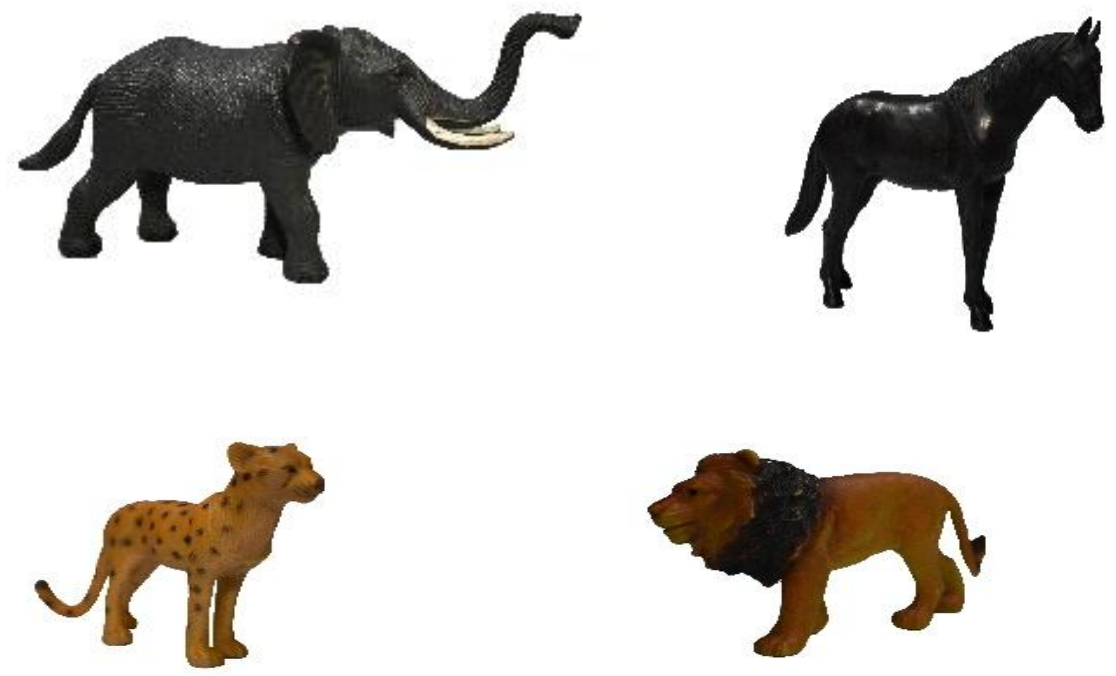

Stimuli of $3^{\text {rd }}$ experiment

Appendix-4

Table of Responses of Picture Test: HFA Children

\begin{tabular}{|c|c|c|c|c|c|c|c|c|c|c|}
\hline Participant & 1 & 2 & 3 & 4 & 5 & 6 & 7 & 8 & 9 & 10 \\
\hline 1. $\mathrm{MA}_{1}$ & $\sqrt{ }$ & $\sqrt{ }$ & $\sqrt{ }$ & $\sqrt{ }$ & $\sqrt{ }$ & $\sqrt{ }$ & $\sqrt{ }$ & $\sqrt{ }$ & $\sqrt{ }$ & $\sqrt{ }$ \\
\hline 2. $\mathrm{MA}_{2}$ & $\sqrt{ }$ & $\begin{array}{l}\text { cinta } \\
\text { kore }\end{array}$ & $\sqrt{ }$ & $\begin{array}{c}\text { kane } \\
\text { hat die } \\
\text { rakhe }\end{array}$ & $\begin{array}{l}\text { bacca } \\
g^{\text {fi } u m a e ~}\end{array}$ & $\sqrt{ }$ & $\mathrm{x}$ & $\sqrt{ }$ & hat $u_{n}^{\text {thacce }}$ & $\begin{array}{l}\text { bofe } \\
a^{\text {he }} \text { e }\end{array}$ \\
\hline 3.PO & $\sqrt{ }$ & $\sqrt{ }$ & $\sqrt{ }$ & $\sqrt{ }$ & $\sqrt{ }$ & $\sqrt{ }$ & $\sqrt{ }$ & $\sqrt{ }$ & $\sqrt{ }$ & $\sqrt{ }$ \\
\hline 4.SH & $\sqrt{ }$ & $\begin{array}{l}\text { haci } \\
\text { dise }\end{array}$ & $\sqrt{ }$ & $\begin{array}{c}\text { kane } \\
\text { hat die } \\
\text { rak }^{\mathrm{h}}\end{array}$ & $\begin{array}{l}\operatorname{mat}_{n}^{\text {tha }} \\
\text { batha }\end{array}$ & $\begin{array}{l}\text { darie } \\
\text { ache }\end{array}$ & $\sqrt{ }$ & $\begin{array}{l}\text { cupcu } \\
\text { p fobai } \\
\text { bofe } \\
\text { thake }\end{array}$ & $\begin{array}{l}\text { cricket khela } \\
\int \text { fik }^{\text {he }}\end{array}$ & $\begin{array}{c}\text { golpo } \\
\text { kore }\end{array}$ \\
\hline $5 . \mathrm{AB}$ & $\sqrt{ }$ & $\begin{array}{l}\text { kanna } \\
\text { korc }^{\mathrm{h}} \mathrm{e}\end{array}$ & $\sqrt{ }$ & $\begin{array}{l}\text { kanna } \\
\text { korch } e\end{array}$ & $\sqrt{ }$ & $\sqrt{ }$ & $\mathrm{x}$ & $\sqrt{ }$ & $\mathrm{x}$ & $\begin{array}{l}\text { kanna } \\
\text { korch }^{\text {he }}\end{array}$ \\
\hline 6.SR & $\sqrt{ }$ & $\begin{array}{l}\text { muk }^{\mathrm{h}} \\
\mathrm{d}^{\mathrm{f}} \text { ore } \\
\text { ache }^{\mathrm{h}} \mathrm{C}\end{array}$ & $\sqrt{ }$ & $\sqrt{ }$ & $\begin{array}{l}\text { kole } \\
\mathrm{d}^{\mathrm{f}} \text { ore } \\
\mathrm{ac}^{\mathrm{h}} \mathrm{e}\end{array}$ & ayul & $\begin{array}{c}\text { kane } \\
\text { hat } \\
\operatorname{diec}^{\text {he }} \text { e }\end{array}$ & $\mathrm{x}$ & k $^{\text {h }}{ }^{1 a d} d^{\text {f }}$ ula kore & $\begin{array}{l}\text { bofe } \\
\text { thake }\end{array}$ \\
\hline 7.AN & $\sqrt{ }$ & $\sqrt{ }$ & $\sqrt{ }$ & $\sqrt{ }$ & $\mathrm{x}$ & $\sqrt{ }$ & $\begin{array}{c}\text { lopa } \\
\text { mis } \\
\text { amake } \\
\text { boke }\end{array}$ & $\mathrm{x}$ & Football & $\mathrm{x}$ \\
\hline 8.AS & $\sqrt{ }$ & $\sqrt{ }$ & $\mathrm{x}$ & $\mathrm{x}$ & $\sqrt{ }$ & $\mathrm{x}$ & $\sqrt{ }$ & $\sqrt{ }$ & $\mathrm{x}$ & babu \\
\hline
\end{tabular}




\section{Appendix -5}

Table of Responses of Symbolic Play Test: HFA Children

\begin{tabular}{|c|c|c|c|c|c|c|c|c|c|c|c|c|c|c|c|c|}
\hline \multirow{2}{*}{$\begin{array}{c}\text { Participan } \\
\mathbf{t}\end{array}$} & \multicolumn{4}{|c|}{ Elephant } & \multicolumn{4}{|c|}{ Horse } & \multicolumn{4}{|c|}{ Tiger } & \multicolumn{4}{|c|}{ Lion } \\
\hline & 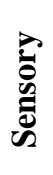 & 苞 & - & | & 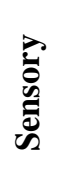 & Oّ & 总 & D: & 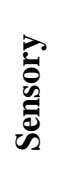 & Oే & - & D. & 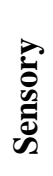 & 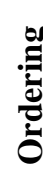 & 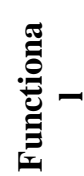 & D \\
\hline $\mathrm{MA}_{1}$ & $\sqrt{ }$ & $\mathrm{x}$ & $\sqrt{ }$ & $\sqrt{ }$ & $\sqrt{ }$ & $\mathrm{x}$ & $\sqrt{ }$ & $\sqrt{ }$ & $\sqrt{ }$ & $\mathrm{x}$ & $\sqrt{ }$ & $\sqrt{ }$ & $\sqrt{ }$ & $\mathrm{x}$ & $\sqrt{ }$ & $\sqrt{ }$ \\
\hline $\mathrm{MA}_{2}$ & $\sqrt{ }$ & $\mathrm{x}$ & 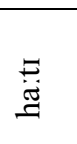 & $\sqrt{ }$ & $\sqrt{ }$ & $\mathrm{x}$ & 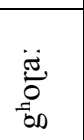 & $\sqrt{ }$ & $\sqrt{ }$ & $\mathrm{x}$ & 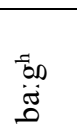 & $\sqrt{ }$ & $\sqrt{ }$ & $\mathrm{x}$ & 营 & $\sqrt{ }$ \\
\hline $\mathrm{PO}$ & $\sqrt{ }$ & $\sqrt{ }$ & $\sqrt{ }$ & $\sqrt{ }$ & $\sqrt{ }$ & $\sqrt{ }$ & $\sqrt{ }$ & $\sqrt{ }$ & $\sqrt{ }$ & $\mathrm{x}$ & $\sqrt{ }$ & $\mathrm{x}$ & $\sqrt{ }$ & $\sqrt{ }$ & $\sqrt{ }$ & $\mathrm{x}$ \\
\hline $\mathrm{SH}$ & $\sqrt{ }$ & $\mathrm{x}$ & $\sqrt{ }$ & $\mathrm{x}$ & $\sqrt{ }$ & $\mathrm{x}$ & $\sqrt{ }$ & $\mathrm{x}$ & $\sqrt{ }$ & $\mathrm{x}$ & $\sqrt{ }$ & $\mathrm{x}$ & $\sqrt{ }$ & $\mathrm{x}$ & $\sqrt{ }$ & $\mathrm{x}$ \\
\hline $\mathrm{AB}$ & $\mathrm{x}$ & $\mathrm{x}$ & $\sqrt{ }$ & $\mathrm{x}$ & $\mathrm{x}$ & $\mathrm{x}$ & $\sqrt{ }$ & $\mathrm{x}$ & $\mathrm{x}$ & $\mathrm{x}$ & $\sqrt{ }$ & $\mathrm{x}$ & $\mathrm{x}$ & $\mathrm{x}$ & $\sqrt{ }$ & $\mathrm{x}$ \\
\hline $\begin{array}{l}\text { SR } \\
\text {. }\end{array}$ & $\sqrt{ }$ & $\mathrm{X}$ & 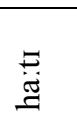 & $\mathrm{x}$ & $\sqrt{ }$ & $\mathrm{x}$ & 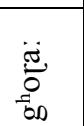 & $\mathrm{x}$ & $\sqrt{ }$ & $\mathrm{x}$ & 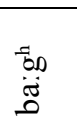 & $\mathrm{x}$ & $\sqrt{ }$ & $\mathrm{x}$ & 苛 & $\mathrm{x}$ \\
\hline AN & $\sqrt{ }$ & $\mathrm{x}$ & & $\sqrt{ }$ & $\sqrt{ }$ & $\mathrm{x}$ & 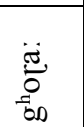 & $\sqrt{ }$ & $\sqrt{ }$ & $\mathrm{x}$ & $\sqrt{ }$ & $\sqrt{ }$ & $\sqrt{ }$ & $\mathrm{x}$ & $\sqrt{ }$ & $\mathrm{x}$ \\
\hline AS & $\mathrm{x}$ & $\mathrm{x}$ & 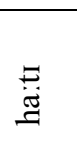 & $\sqrt{ }$ & $\mathrm{x}$ & $\mathrm{x}$ & 苛 & $\mathrm{x}$ & $\mathrm{x}$ & $\mathrm{x}$ & 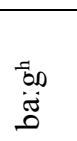 & $\sqrt{ }$ & $\mathrm{x}$ & $\mathrm{x}$ & $\stackrel{8}{\stackrel{\Xi}{\tilde{n}}}$ & $\sqrt{ }$ \\
\hline
\end{tabular}

